\title{
Modern technologies of wastewater treatment for low-capacity facilities
}

\author{
Elena Gogina ${ }^{1, *}$, Olga Ruzhitskaya $^{2}$ and Varvara Shmalko ${ }^{1}$ \\ ${ }^{1}$ Moscow State University of Civil Engineering, 26, Yaroslavskoe shosse, Moscow, 129337, Russia \\ ${ }^{2}$ Peoples' Friendship University of Russia, 6 Miklukho-Maklaya St., Moscow, 117198, Russia
}

\begin{abstract}
The article touches upon the issues of wastewater treatment on the facilities of small capacity. The brief analysis of the current state is given. The paper reveals main problems to be solved that consider small treatment plant operation, its influence on environment and most prospective solutions. The article considers the developed wastewater treatment technologies, as well as the implementation of these technologies on the patented small plants for deep biological treatment, including with the removal of phosphates at the tertiary treatment stage.
\end{abstract}

\section{Introduction}

The analysis of modern solutions for wastewater treatment at small treatment plants showed that such constructions are carried out in the form of block-modular systems. They can be made from metal, plastic, rarely, reinforced concrete. Such constructions are used both as individual plants and in low capacity facilities in the cottage towns, recreational and therapeutic stand-alone institutions, leisure centers, etc. Certain proposed technological schemes include the use of feed material. Such technologies create conditions for the use of facilities in a "ragged" mode, when the water comes to treatment plants unevenly during the month/year. The feed material allows to save the biomass and to ensure the maximum fast startup of biological process of treatment plants [1,2].

Small wastewater treatment plants are often enough operated in an extended aeration mode. The performance of such facilities is from 1.5 up to $200 \mathrm{~m}^{3} /$ day. The constructions constitute series-connected reactors. The technology is usually designed so that the wastewater being processed; moving from the tank into the tank, pass each cycle of biological treatment. A gradual adaptation of activated sludge microorganisms with phased dilution of wastewater processed with the returnable active sludge in the course of their movement is achieved. This technology makes it possible to maintain the disposal of wastewaters with elevated concentrations of contaminants toxic for active sludge (synthetic surfactants, chlorine, manganese); however, it requires large enough volumes and space [3].

\section{Technology for deep removal of ammonia nitrogen}

In the basic technological scheme that was applied for the reconstruction the goal is

${ }^{*}$ Corresponding author: goginaes@mgsu.ru 
achieved during the biological treatment of wastewater in the aeration tank, divided into four successive anoxic and aerobic zones, which are supplied with wastewater and active sludge in a certain percentage. Next, the sludge mixture is sent to the secondary clarifier for separation. Thus, the developed method has the following advantages:

- it increases the degree of treatment of wastewater from nitrogen of ammonium salts, the concentrations of which in treated water are below the determination limit;

- it increases the oxidative capacity of the system; while according to studies conducted, the organic contamination load on the sludge can be increased 2.6 times.

Based on the underlying schema developed different parameters can be varied, depending on the treatment quality requirements and local conditions. For example, it is possible to change the liquid waste processing time, number of zones and the retention time in them. The averaged results of samples' chemical analyses of the aeration tank operation are shown in Table 1.

Table 1. Values of operation.

\begin{tabular}{|c|c|}
\hline Indicators & Values \\
\hline BOD load, mg/g/day & 520 \\
\hline MLSS [g/l] & 3 \\
\hline $\mathrm{N}-\mathrm{NH}_{4}[\mathrm{mg} / \mathrm{l}]$ (in) & $17-20$ \\
\hline $\mathrm{N}^{-N_{4}} 4[\mathrm{mg} / \mathrm{l}]$ (out) & Below the determination limit (BDL) \\
\hline $\mathrm{N}-\mathrm{NO}_{2}[\mathrm{mg} / \mathrm{l}]$ (out) & Below the determination limit (BDL) \\
\hline $\mathrm{N}-\mathrm{NO}_{3}[\mathrm{mg} / \mathrm{l}]$ (out) & 4.5 \\
\hline HRT $[\mathrm{h}]$ & $7-8$ \\
\hline
\end{tabular}

Based on the underlying technology the constructions of small treatment plants were also developed. So, the model "Water Lily" with capacity of $1-4 \mathrm{~m}^{3} /$ day has been developed (patent for invention No. 2182133). The construction of this plant resembles a two-tiered clarifier. The internal cylindrical tank contains the two-tiered clarifier, sediment annular trough of which was in the center of the tank, and at the end of its cone a hole was provided for the sediment deposited in the septic chamber. The bioreactor with anoxoc and aerobic divisions and secondary clarifier with highly porous filter are in the external tank. The module with planar loading is mounted in the aerobic zone. Aeration is done using a compressor via pneumatic small-bubble aerators $[5,6]$.

Compared to some models from other manufacturers, in the small plant Water Lily hydraulic motion mode of wastewater and sludge mixture in the bioreactor is close to the displacement conditions, and channeling of untreated water in it is practically excluded. In addition, the biological treatment process is carried out in the mode of denitri-nitrification, which allows reducing the concentration of ammonia nitrogen salts in treated water. Purified water easily filters through loading any device without its silting and environment contamination. However, the presence of septic chamber maintains the problem of disposal of sediments fermented by anaerobic sludge (1-3 times a year). The disadvantages of this installation also include the unfortunate location of the secondary clarifier, on an inclined semiarc bottom of which the activated sludge was periodically collected and putrefied that reduced the overall efficiency of wastewater treatment.

Taking into account the deficiencies, in conjunction with Aqua Hold company a smallsized plant UBS Aqua-Aero (utility model patent No. 120417) was designed using singlesludge technology (by patent for purification method No. 2185338 with the priority from 05/31/2000) $[2,7,8]$.

Wastewater treatment on the installation is carried out as follows: the original wastewater is supplied by sewage collector $d=100 \mathrm{~mm}$ through the transfer tube on the grid and later to the anoxic chamber of denitrification, the recirculated active sludge settling in the clarifier is also continuously pumped here in a certain amount using the air lift $[9,10]$. 
Large trash is held up on the grid: rags, newsprint, toilet articles, etc. Periodically trash shall be removed from the grid (the frequency is determined empirically) and together with household waste material disposed to a landfill. Oxidation of organic matter due to oxygen forming during the recovery process of nitrogen of nitrates to nitrogen-free occurs in the denitrification chamber. The biological method of removing ammonium salts from wastewater is the most natural and acceptable in specific circumstances. Stirring the mixture is carried out with a pneumatic agitator.

A mixture of wastewater and sludge under semi-submersible bulkhead flows into the nitrification chamber equipped with planar loading modules. Permanent fine-bubble aeration of the treated wastewater in the mixture with active sludge around the nitrification chamber volume provides intensive stirring of the mixture and oxygenation, which creates favorable conditions for biological degradation of remaining part of the organic contaminants. Biofilm growing on the planar inert carrier provides resistance of structures to various extreme situations (lack of electricity, salvo emissions of concentrated waters, temporary lack of tenants, etc.) and provides time to optimal operation mode of facilities of 2-3 days.

At the end of the nitrification chamber wastewater with active sludge on the pipe goes into the centre tube of the clarifier of vertical type. Being reflected from the dissector, purified water rises up to the peripheral collecting tray with a serrated overfall, activated sludge under hydrostatic pressure falls to a sump pit, creating a suspended layer, through which wastewater is filtered and clarified. Clarified water overflows from the tray into the chamber of purified water equipped with a submersible pump or by gravity is sewered in the reservoir.

The settling active sludge is constantly pumped from the sump pit using the air lift into the denitrification chamber. Periodically (frequency is determined empirically and through calculation), a shut-off and control valve for pumping the excess (with a high degree of mineralization) of sludge into the container for excessive active sludge equipped with filter cloth is enabled on the air lift in the automatic mode. The filtrate is poured from the container along with the recirculating sludge into the anoxic area. When filling the container with the dehydrated sediment, filter cloth (in the form of a bag) is removed, the sediment can be used on planting or cultivation beds (approximately 1 time in 1-3 months).

Recirculation and aeration of the wastewater and activated sludge mixture is done using a compressor installed in the basement of the building. Table 2 shows the average sanitation indicators of source waters and waters treated at sewage plant on multiple objects.

Table 2. Treatment indicators.

\begin{tabular}{|c|c|c|}
\hline Indicators & In & Out \\
\hline $\mathrm{BOD}_{\text {tot }}[\mathrm{mg} / \mathrm{l}]$ & 324 & $5-10$ \\
\hline Suspended solids [mg/l] & 290 & $5-10$ \\
\hline $\mathrm{N}^{-\mathrm{NH}_{4}[\mathrm{mg} / \mathrm{l}]}$ & 47 & $0.3-0.2$ \\
\hline $\mathrm{N}-\mathrm{NO}_{2}[\mathrm{mg} / \mathrm{l}]$ & - & 0.2 \\
\hline $\mathrm{N}-\mathrm{NO}_{3}[\mathrm{mg} / \mathrm{l}]$ & - & $5.0-9.0$ \\
\hline $\mathrm{P}_{-} \mathrm{PO}_{4}[\mathrm{mg} / \mathrm{l}]$ & 11.2 & $0.5-3.0$ \\
\hline
\end{tabular}

According to the sanitary and chemical indicators on the operation of the plants, it is possible to conduct calculations and draw conclusions on the work of the biochemical wastewater treatment system in this building.

The wastewater treatment time in the treatment system is about 8 hours. The dose of the sludge is on average $3.5 \mathrm{~g} / \mathrm{l}$, and the ash content of the activated sludge is 0.3 .

The oxidation rate is calculated for heterotrophic single-sludge systems. According to calculations, the average oxidation rate at a specific wastewater treatment time is $6.9 \mathrm{mg}$ $\mathrm{BOD} / \mathrm{g} * \mathrm{~h}$. According to literary data and experience with biological wastewater treatment systems, it is known that for the normal functioning of biological systems and maintenance 
of the activated sludge in a working state the oxidation rate shall be higher than $10 \mathrm{mg}$ $\mathrm{BOD} / \mathrm{g}^{*} \mathrm{~h}$, and the load shall be approximately $300 \mathrm{mg} \mathrm{BOD} / \mathrm{g} *$ day. Thus, having all the essential operating characteristics of the biological purification reactor, we can determine the rate of nitrification and denitrification. The calculations showed that the rate of nitrification and denitrification is very small and is 3.8 and $3.5 \mathrm{mg} / \mathrm{g} * \mathrm{~h}$, respectively.

Figure 1 shows the dependence of the specific nitrification rate from the ammonia nitrogen concentration in treated water. This graph shows the system work involving the heterotrophic nitrification bacteria. This system is fully subject to the laws of the biological nitrification process involving these microorganisms. This fact indicates that the age of active sludge in the system is high, the number of nitrification bacteria is enough for two nitrification stages and the processes of nitrification must be deep.

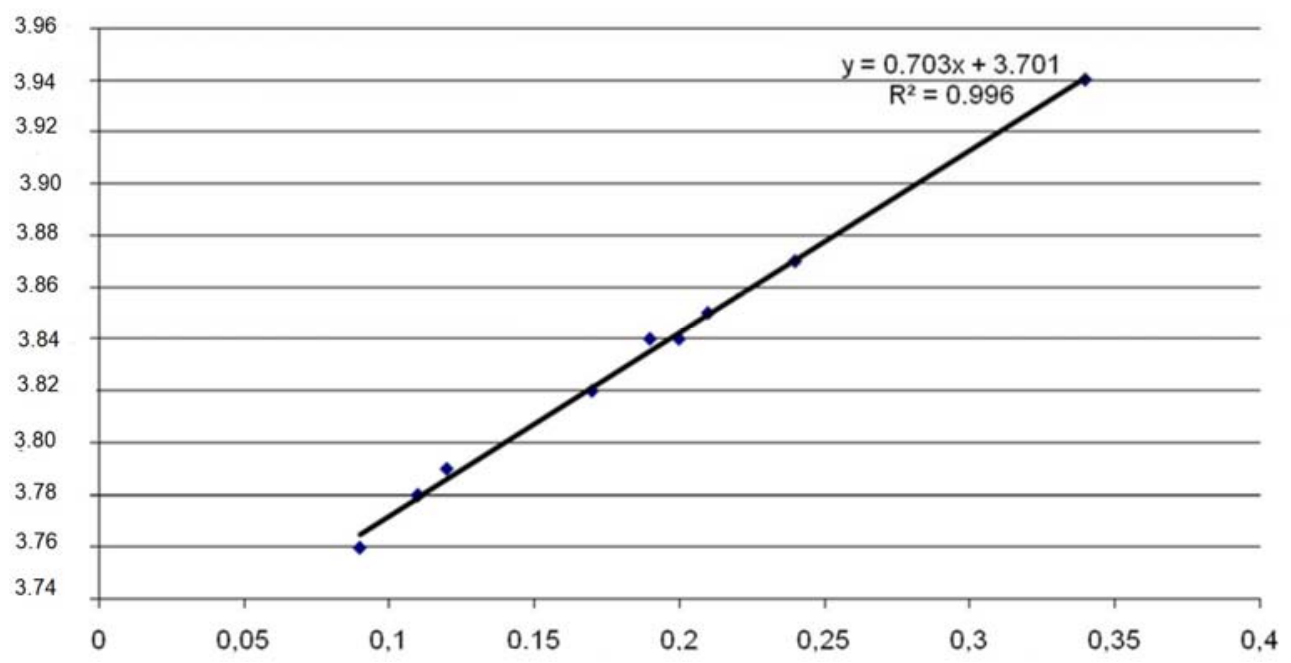

Fig. 1. Dependence of nitrification rate (Y-axis) to $\mathrm{N}-\mathrm{NH}_{4}$ concentration in treated water (X-axis).

A similar dependence diagram of the specific denitrification rate from BOD of the purified water (Figure 2) was plotted to assess the work of the heterotrophic bacteria, which carry out denitrification of wastewater with simultaneous oxidation of organic substances. The resulting dependency indicates the successful denitrification processes in the presence of good conditions for bacteria. That is, the dependency data confirm again the above assumptions that this system can work stably and implement processes of oxidation of organic substances, nitrification and denitrification. For this, the system has the main condition, which is the presence of the nitrification activated sludge. However, due to small BOD loads and a large dose of active sludge the inhibition of these processes in the system occurs.

Based on the analysis of wastewater treatment plant biological system operation, we can conclude on the successful use of a stable system, which is based on the application of nitrification active sludge consisting of heterotrophic nitrification bacteria.

Particularly difficult is the process of combining the technologies of biological nutrients removal within a single facility. Therefore, the proposed technology of deep biological purification from nitrogen compounds can be supplemented with tertiary treatment from phosphorus compounds using a biochemical method. 


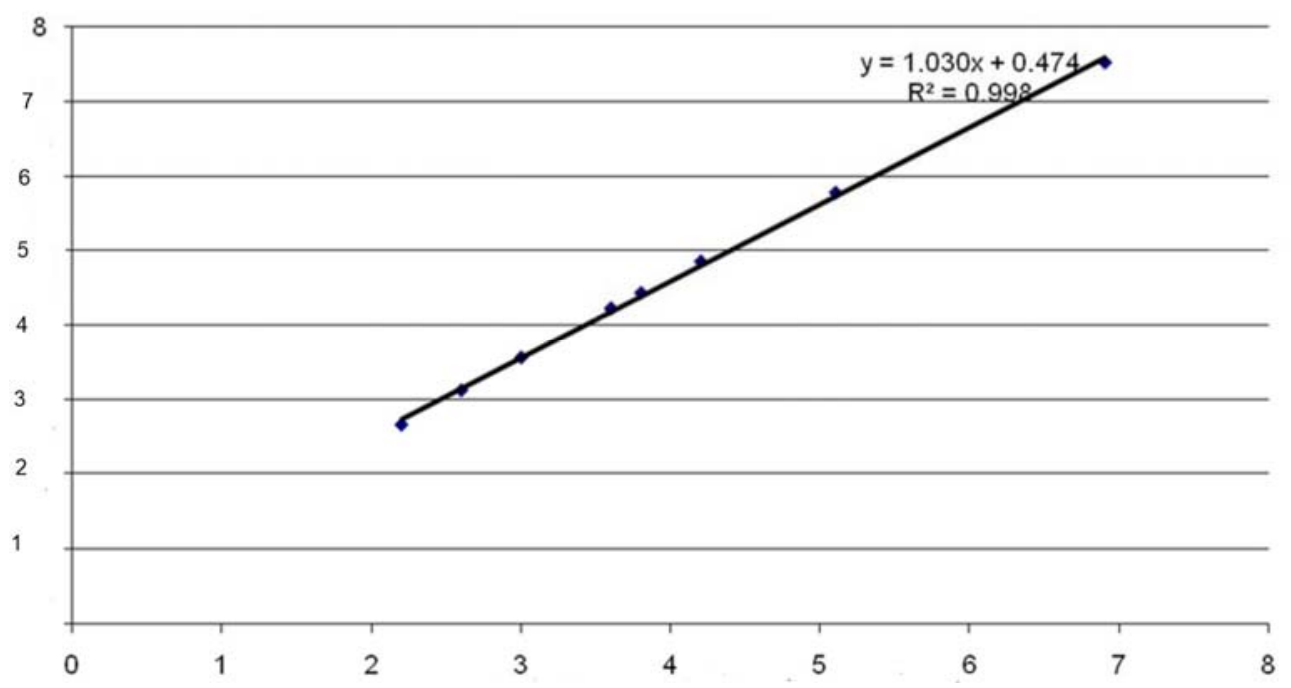

Fig. 2. Dependence of denitrification rate (Y-axis) to BOD concentration in purified wastewater (Xaxis).

\section{Wastewater tertiary treatment technology for removal of phosphates}

Removal of phosphates is proposed with the use of bioreactor reinforced with feed material. The body of the tertiary treatment bioreactor is mounted the reinforced feed material with the following technical characteristics:

- source material PVC 158;

- sheet thickness $4 \mathrm{~mm}$;

- volume weight $25 \mathrm{~kg} / \mathrm{m}^{3}$;

- $\quad$ specific surface area $190 \mathrm{~m}^{2} / \mathrm{m}^{3}$;

- reinforcement with a steel wire Grade Steel 3.

The retention time of water to be treated is 2-4 hours.

Tertiary treatment bioreactor is equipped with an aeration system and works in the flowing mode without circulation and return of the active sludge. As far as feed material is overgrowing with biofilm, it is necessary to regenerate it by washing. The need for washing the feed material is associated with a decreased quality of water purification from phosphates in the course of the feed material overgrowing with biofilm.

Treatment in the bioreactor occurs mainly due to physical and chemical processes of phosphate coagulation with iron ions that originate from the metal, which is located in the feed material, subject to processes of electrochemical corrosion. When the feed is overgrowing with biofilm, metal surface area contact with water is reduced, and the purification effect is decreased.

Constant aeration increases the amount of dissolved oxygen in the bioreactor, which in turn accelerates the corrosion processes. With a large content of dissolved oxygen in the water, that is peculiar to little BOD values of incoming waste liquids even at moderate intensity of aeration, film is formed on metal that protects the metal from corrosion and thereby reduces the effect of phosphate removal. After regeneration, the treatment efficiency is recovered, it can therefore be assumed that the decreased effect is not due to the protective films on metal, but due to the biological film forming on the feed material, because the protective film cannot be deleted by washing. Probably, after regeneration (for 
the period until a biological film forms on the feed material), a process of protective film formation on the metal occurs, further developing microorganisms of the biological films erode the protective film, and when flushing it during washing, the surface of the metal is released from the corrosion products, and the corrosion intensity is resumed.

Phosphate removal efficiency, when using the proposed method of tertiary treatment, reaches $99 \%$.

Additionally, in parallel with the decrease in the phosphate concentration, a decrease in the contamination by such indicators as $\mathrm{BOD}_{5}$ and suspended substances is observed. The effect of the reinforced feed material on the second stage of nitrification and reduction of ammonia nitrogen was also established. Basic operation data of the tertiary treatment bioreactor (with the aeration duration of 4 hours) are shown in Table 3.

Table 3. Treatment indicators.

\begin{tabular}{|l|c|c|}
\hline Indicators, $\mathrm{mg} / \mathrm{l}$ & Source water & Purified water \\
\hline Phosphates & $2-6$ & $\mathrm{BDL}^{*}-1$ \\
\hline BOD 5 & $5-20$ & $\mathrm{BDL}^{*}-10$ \\
\hline Ammonium nitrogen & $\mathrm{BDL}^{*}-20$ & $\mathrm{BDL}^{*}-16$ \\
\hline Suspended solids & $\mathrm{BDL}^{*}-25$ & $\mathrm{BDL}^{*}-10$ \\
\hline
\end{tabular}

Thus, the tertiary treatment bioreactor can be used not only for final purification from phosphates, but also for the tertiary treatment from organic substances and suspended solids.

\section{Conclusions}

The presented technologies can be successfully applied for wastewater treatment at the facilities of low capacity. Separate application of methods of deep purification from ammonium nitrogen and phosphate within one facility allows to reach normative indicators for fishery waters, when treating the domestic wastewaters.

\section{References}

1. E. Gogina, I.Gulshin, Procedia Eng., 153, 189-194 (2016)

2. E. Gogina, A. Pelipenko, MATEC Web of Conf., 73, 03007 (2016)

3. Sh. Yang, P. Jin, C. Wang, Q. Zhang, X. Chen, Wat. Sci. and Technol., 75, 6, 15001511 (2017)

4. N. Makisha, Procedia Eng., 165, 1092-1097 (2016)

5. O. Ruzhitskaya, O. Yantsen, Int. J. of App. Eng. Res., 11, 5, 3496-3498 (2016)

6. H. Jae-Hoon, J. Church, L. Seung-Jin, P. Jungsu, and L. W. Hyoung, Env. Eng.Sci., 33, $11,882-897$ (2016)

7. Y. Yang, F. Tang, X. Su, H. Yin, F. Ge, Water Sci. and Tech., 74, 11, 2727-2735 (2016)

8. H. Wang, Z.Zou, X. Xiao, D. Chen, K. Yan, Wat. Sci and Tech, 73, 11, 2689-2696 (2016)

9. A. Kulakov, N. Makisha, MATEC Web of Conf., 112, 10019 (2017)

10. N. Makisha, T.Kazimirova, MATEC Web of Conf., 144, 04013 (2018) 